\title{
ANALISA PENANGANAN SEDIMENTASI DENGAN SEPASANG JETTY PADA MUARA SUNGAI SERAYU
}

\author{
Novi Andhi Setyo Purwono' ${ }^{1}$, Iwan Rustendi'), Fauzan Angga Musthafa ${ }^{1)}$, dan Rizka \\ Riadianto $^{1)}$
}

1) Program Studi Teknik Sipil, Universitas Wijayakusuma, Purwokerto, Jawa Tengah

novi_andhisp@yahoo.com

\begin{abstract}
The estuary functions as a discharge from the river, especially when it floods into the sea. The movement of currents from the sea and also the flow of water from upstream causes sedimentation problems in the estuary. Jetty building planning is required for handling sediment at the estuary of the Serayu River, which is planned with $35721 \mathrm{~m}^{2}$ construction area of a pair Wind data analysis for 10 years is carried out using software WRPLOT, AUTOCAD, and Google Earth. Concrete quality for making tetrapod using concrete $\left(f^{\prime} \mathrm{c}\right) 31.2 \mathrm{MPa}$. The tetrapods used have a weight, width, height of 7.6 tons, 2.69 $m$, and $2.24 \mathrm{~m}$, respectively. Geotextiles used in the jetty building design are $44781.68 \mathrm{~m}$ long. Security of the Serayu River estuary requires two pairs of the jetty, the jetty to the right of the estuary requires $778 \mathrm{~m}$ length and $34.6 \mathrm{~m}$ width, while the jetty to the left of the estuary requires $560 \mathrm{~m}$ length and $34.6 \mathrm{~m}$ width. The budget plan for the construction of a jetty for handling sediment at the estuary of the Serayu River is IDR 438,708,114,000.00.
\end{abstract}

Keywords: jetty, estuary, sedimention

\begin{abstract}
ABSTRAK
Muara sungai berfungsi sebagai pembuangan debit sungai terutama pada waktu banjir ke laut. Pergerakan arus dari laut dan juga aliran air dari hulu menyebabkan permasalahan sedimentasi pada muara. Perencanaan bangunan jetty diperlukan untuk penanganan sedimen muara Sungai Serayu, dimana direncanakan dengan luas bangunan sepasang jetty $35721 \mathrm{~m} 2$. Analisa data angin selama 10 tahun dilakukan dengan menggunakan program komputer WRPLOT, AUTOCAD, dan Google Earth. Mutu beton untuk pembuatan tetrapod menggunakan beton ( $f_{c}$ ') $31.2 \mathrm{MPa}$. Tetrapod yang digunakan mempunyai berat, lebar, tinggi berturut-turut 7.6 ton, $2.69 \mathrm{~m}$, dan $2.24 \mathrm{~m}$. Geotekstil yang digunakan pada perencanaan bangunan jetty sepanjang $44781.68 \mathrm{~m}$. Pengamanan muara Sungai Serayu memerlukan dua pasang jetty, jetty di sebelah kanan muara diperlukan panjang $778 m$ dan lebar 34.6 m sedangkan jetty di sebelah kiri muara diperlukan panjang $560 \mathrm{~m}$ dan lebar $34.6 \mathrm{~m}$. Perhitungan rencana anggaran biaya pembangunan bangunan jetty untuk penanganan sedimen muara Sungai Serayu sebesar Rp 438,708, 114,000.00.
\end{abstract}

Kata kunci: jetty, muara sungai, sedimen 


\section{PENDAHULUAN}

Muara Sungai Serayu terletak di wilayah Kabupaten Cilacap, tepatnya di Kecamatan Adipala dan Kecamatan Kesugihan. Menurut Triatmodjo (1999), muara sungai berfungsi sebagai pembuangan debit sungai terutama pada waktu banjir ke laut. Letak muara sungai yang berada di ujung hilir menyebabkan debit aliran dimuara lebih besar daripada sungai di wilayah hulu. Pasir yang melintas di depan muara akan terdorong oleh gelombang masuk ke muara kemudian diendapkan. Transpor sedimen sepanjang pantai juga sangat berpengaruh terhadap pembentukan endapan dimuara.

Pada musim penghujan air banjir dapat mengerosi endapan sedimen sehingga sedikit demi sedikit muara sungai dapat terbuka kembali. Pada saat musim kemarau debit aliran sungai mengecil, sedangkan gelombang dari arah laut besar dan sedimen dari arah saluran sungai serayu terhambat dimuara sehingga terjadi pengikisan dibagian tepi. Selama proses penutupan dan pembukaan kembali biasanya disertai dengan proses membeloknya muara sungai dalam arah yang sama dengan arah transpor sedimen sepanjang pantai.
Identifikasi perubahan transport sedimen atau perubahan garis pantai selain menggunakan model juga dapat menggunakan bantuan citra satelit dengan resolusi sedang (Aryastana, Ardantha, \& Candrayana, 2018; Aryastana, Ardantha, \& Rahadiani, 2018; Aryastana et al., 2018; Ardantha et al., 2019). Permasalahan yang sering dijumpai adalah banyaknya endapan dimuara sungai sehingga tampang alirannya menjadi kecil yang dapat mengganggu pembuangan debit sungai ke laut.

Beberapa studi perencanaan jetty sebagai bangunan pengendali sedimen antara lain perencanaan jetty dengan menggunakan material geobag untuk menangani penumpukan sedimen pada muara Tukad Pangi, Kabupaten Badung, Provinsi Bali (Werdi \& Eryani, 2020). Selain itu, perencaan jetty dengan material bronjong juga dilakukan untuk mengatasi penutupan sedimen pada muara Tukad Melangit di Kabupaten Klungkung (Suryawan, Eryani, \& Rahadiani, 2019). Jetty juga direncanakan untuk menanggulangi permasalahan sedimen pada muara Sungai Batu Putih Kabupaten Aceh Barat (Riandi, Ikhsan, \& Amir, 2015). Perencaaan 2 buah jetty juga dilakukan pada proyek Offshore Site 
Development Kilang Bontang, Kalimantan Timur (Muchlisoh, 2016).

Jetty adalah bangunan tegak lurus pantai yang diletakan pada satu atau kedua sisi muara sungai yang berfungsi untuk mencegah terjadinya luapan sungai oleh endapan sedimen pantai. Pembangunan jetty di muara Sungai Serayu diharapkan dapat mengurangi pengikisan tanah disekitar muara sungai dan mengurangi endapan sedimen dimulut sungai, untuk itu perlu dilakukan kajian pembangunan jetty di muara Sungai Serayu.

\section{KAJIAN PUSTAKA}

\subsection{Angin}

Triatmodjo 1999 menyatakan bahwa angin merupakan sirkulasi yang kurang lebih sejajar dengan permukaan bumi. Angin terjadi akibat adanya perubahan atau pun perbedaan suhu antara suatu tempat dengan tempat yang lain. Dalam perhitungan ini digunakan kecepatan angin maksimum, dimaksudkan agar dapat diperoleh kondisikondisi gelombang yang ekstrim. Angin maksimum yang digunakan, terlebih dahulu dikoreksi untuk mendapatkan factor stress-angin (windstress factor).

\subsection{Fetch}

Coastal Engineering Research Center 2006, menyatakan bahwa Fetch adalah daerah pembangkit gelombang laut yang dibatasi oleh daratan yang mengelilingi laut tersebut. Daerah fetch adalah daerah dengan kecepatan angin konstan. Sedangkan jarak fetch merupakan jarak tanpa rintangan dimana angin sedang bertiup. Arah fetch diambil arah tenggara, arah selatan dan arah barat daya, yang besarnya dapat dihitung sebagai berikut (Anonim, 2006):

$$
\mathrm{F}_{\text {eff }}=\frac{\sum X i \cos \alpha}{\sum \cos \alpha}
$$

dimana:

\section{$\mathrm{F}_{\text {eff }}$ : fetch efektif}

$\mathrm{X}_{\mathrm{i}}$ : panjang segmen fetch yang diukur dari titik observasi gelombang ke ujung akhir fetch.

$\alpha$ : deviasi pada kedua sisi dari arah angin, dengan menggunakan pertambahan $6^{\circ}$ sampai dengan $42^{\circ}$ pada kedua sisi dari arah angin.

\subsection{Mawar Gelombang}

Coastal Engineering Research Center 2006, menyatakan bahwa Waverose menggambarkan frekuensi kejadian pada tiap arah mata angin dan kelas ketinggian gelombang pada lokasi dan waktu yang telah ditentukan. Waverose menghasilkan nilai tinggi gelombang air laut dalam satuan centimeter $(\mathrm{cm})$ atau meter $(\mathrm{m})$. 


\subsection{Peramalan Tinggi dan Periode Gelombang}

Coastal Engineering Research

Center 1984 menyatakan bahwa metode yang digunakan untuk perhitungan gelombang berdasarkan data angin dan medan pembangkitan gelombang adalah metode SMB 1984 (Anonim, 1984). Metode SMB 1984, nilai tinggi gelombang signifikan (Hs) dan periode puncak gelombang (Ts) merupakan fungsi dari kecepatan angina (UA), durasi angin (t), dan panjang fetch $(\mathrm{F})$, dimana:

$$
(\mathrm{Hs}, \mathrm{Ts})=\mathrm{f}(\mathrm{UA}, \mathrm{F}, \mathrm{t})
$$

Nilai UA adalah faktor stress angin $(\mathrm{m} / \mathrm{s})$ yang didefinisikan sebagai:

$$
\mathrm{UA}=0.71 U 10^{1,23}
$$

Fetch efektif, model parametrik yang diekspresikan adalah sebagai berikut:

$$
\frac{g t \min }{U A}=68.80\left(\frac{g F}{U A^{2}}\right)^{\frac{2}{3}}
$$

Nilai kecepatan angin dikonversi dari satuan knot menjadi m/s $(1$ knot $=0.514$ $\mathrm{m} / \mathrm{s}$ ), kemudian menghitung kecepatan angin di laut dengan menggunakan grafik hubungan antara kecepatan angin di laut (Uw) dan di darat (UL).

$$
\mathrm{Uw}=\mathrm{UL} \times \mathrm{R}_{\mathrm{L}}
$$

Setelah mendapatkan nilai $\mathrm{R}_{\mathrm{L}}$ dari grafik SPM 1984 Coastal Engineering Research Center 1984 dalam, maka dapat dicari nilai tinggi signifikan dan nilai periode signifikan dengan menggunakan data kecepatan angin maksimum dan fetch efektif. Tinggi gelombang signifikan (Hs):

$$
\text { Hrms }=\sqrt{\frac{\sum \mathrm{nH} 0^{2}}{\sum \mathrm{n}}}
$$

Hubungan tinggi gelombang signifikan dengan tinggi gelombang root mean square.

$$
\mathrm{Hs}=1.42 \times \mathrm{Hrms} \text {. }
$$

Periode gelombang signifikan (Ts), dihitung dengan rumus periode gelombang root mean square (Trms).

$$
\operatorname{Trms}=\sqrt{\frac{\sum n T 0^{2}}{\sum n}}
$$

Hubungan periode gelombang signifikan dengan periode gelombang root mean square dihitung dengan rumus:

$$
\text { Ts }=1.42 \times \text { Trms }
$$

Periode ulang gelombang pada analisis ini menggunakan metode Gumbel (Fisher Tippett Type I) dan metode Weibull. Berikut adalah analisis periode gelombang dengan data angin 10 tahun:

\subsubsection{Periode ulang Metode Gumbel (Fisher Tippett Type I)}

Menghitung probabilitas bahwa $\mathrm{H}(\mathrm{m})$ tidak terlampaui atau $\left(\mathrm{H}_{\mathrm{s}}<\mathrm{H}_{\mathrm{sm}}\right)$ dengan rumus:

$$
\mathrm{P}_{(\mathrm{Hs} \leq \mathrm{Hsm})}=1-\frac{m-0,44}{N t+0,12}
$$

dimana: 


$\begin{array}{rlr}\mathrm{P}_{(\mathrm{Hs} \leq \mathrm{Hsm})}: & \text { probabilitas dari tinggi } \\ & \text { gelombang representatif } \\ & \text { ke-m yang tidak } \\ & \text { dilampaui. } \\ \text { Hsm } \quad \text { : } & \text { tinggi gelombang urutan } \\ & \text { ke-m } \\ \mathrm{m} \quad & \text { nomor urut tinggi } \\ & \text { gelombang signifikan : } \\ & 1,2,3, \ldots \mathrm{N} \\ \mathrm{NT} & : \text { jumlah } \\ & \text { gelombang } & \\ & \text { pencatatan } & \end{array}$

Tinggi gelombang signifikan untuk periode ulang dihitung dari fungsi distribusi probabilitas, dimana $\hat{A}$ dan B adalah perkiraan dari parameter skala dan lokal yang diperoleh dari analisis regresi linear (Triatmodjo, 1999):

$$
\begin{aligned}
& \mathrm{Hsr}=\hat{\mathrm{A}} \mathrm{yr}+\mathrm{B} \ldots \ldots \ldots \ldots \ldots \ldots \ldots \ldots . . . \\
& \mathrm{yr}=-\ln \left\{-\ln \left(1-\frac{1}{L T r}\right)\right\} \ldots \ldots \ldots . . \\
& \mathrm{ym}=-\ln \{-\ln P(H s \leq H s m)\}
\end{aligned}
$$

Beberapa nilai di atas dapat dihitung parameter $\hat{A}$ dan $\mathrm{B}^{\wedge}$ berdasarkan data Hsm dan ym dengan menggunakan rumus berikut (Triatmodjo, 1999):

$$
\begin{aligned}
\hat{\mathrm{A}} & =\frac{n \sum H s m Y m-\sum H s m \sum y m}{n \sum Y m^{2}-\left(\sum Y m\right)^{2}} \\
\mathrm{~B}^{\wedge} & =\mathrm{Hsm}-\hat{\mathrm{A}} \mathrm{ym} \ldots \ldots \ldots \ldots \ldots \ldots
\end{aligned}
$$

\subsubsection{Metode Weibull}

Metode Weibull untuk hitungan perkiraan tinggi gelombang ekstrim dilakukan dengan cara yang sama seperti metode Fisher Tippet Type I, hanya persamaan dan koefisien yang digunakan disesuaikan dengan metode Weibull. Rumus probabilitas yang digunakan adalah sebagai berikut (Triatmodjo, 1999):

$$
\left.\mathrm{P}_{(\mathrm{Hs}} \leq \mathrm{Hsm}\right)=1-\frac{m-0,22-\frac{0,27}{\sqrt{k}}}{N T+0,2+\frac{0,23}{\sqrt{k}}} \ldots \ldots \ldots .
$$

dimana:

$\mathrm{P}_{(\mathrm{Hs} \leq \mathrm{Hsm})}$ : Probabilitas dari tinggi gelombang representatif ke-m yang tidak dilampaui

Hsm : Tinggi gelombang urutan ke-m

m : Nomor urut tinggi gelombang signifikan: $1,2,3, \ldots \mathrm{N}$

$$
\begin{array}{llr}
\text { NT } & \text { : Jumlah } & \text { kejadian } \\
& \text { gelombang } & \text { selama } \\
& \text { pencatatan } \\
\text { k } \quad & \text { Parameter bentuk, pada } \\
& \text { analisis ini dipakai } \mathrm{k}=2 .
\end{array}
$$

Tinggi gelombang signifikan untuk periode ulang dihitung dari fungsi distribusi probabilitas dengan rumus:

$$
\mathrm{Hsr}=\hat{\mathrm{A}} \mathrm{ym}+\mathrm{B}^{\wedge}
$$

Parameter $\hat{A}$ dan $\mathrm{B}^{\wedge}$ dihitung dengan menggunakan persamaan 14 dan 15 . Setelah dilakukan perhitungan masingmasing model distribusi, kemudian dilakukan perhitungan kala ulang tinggi gelombang untuk tiap arah mata angin. 


\subsection{Gelombang Pecah}

Coastal Engineering Research Center 2006 menyatakan Menghitung tinggi gelombang pecah dan kedalaman gelombang pecah. Gelombang menjalar dari tempat yang dalam menuju ke tempat yang makin lama makin dangkal, pada suatu lokasi tertentu gelombang tersebut akan pecah. Panjang gelombang di laut dalam

$$
\mathrm{L}_{0}=1.56 \mathrm{~T}^{2}
$$

Cepat rambat gelombang:

$$
\mathrm{C}_{0}=\frac{156}{10} \text {. }
$$

Untuk menghitung koefisien reflaksi, dihitung terlebih dahulu arah datang gelombang yang dihitung dengan persamaan berikut:

$$
\operatorname{Sin} \sigma 1=\left\{\frac{C 1}{C 0}\right\} \sin \sigma_{0}
$$

Koefisien reflaksi:

$$
\mathrm{Kr}=\sqrt{\frac{\cos \sigma 0}{\cos \sigma 1}}
$$

Tinggi gelombang di laut dalam ekuivalen dihitung dengan persamaan:

$$
\mathrm{H}^{\prime}{ }_{0}=\mathrm{Kr} \times \mathrm{H}_{0}
$$

Hitung tinggi gelombang pecah:

$$
\frac{H^{\prime} 0}{g T^{2}}
$$

Untuk nilai $\mathrm{H}^{\prime}{ }_{0} / \mathrm{gT}^{2}$ dari grafik penentuan tinggi gelombang pecah. Sehingga tinggi gelombang pecah adalah $\mathrm{Hb}=$ grafik penentuan tinggi gelombang pecah $\mathrm{x} \mathrm{H}^{\prime}{ }_{0}$. Setelah tinggi gelombang diperoleh selanjutnya dihitung kedalaman gelombang pecah $\mathrm{d}_{\mathrm{b}}$ dengan grafik penetuan kedalaman gelombang. Dengan grafik penentuan kedalaman gelombang maka, kedalaman gelombang pecah adalah $\mathrm{d}_{\mathrm{b}}=$ grafik penentuan kedalaman gelombang x tinggi gelombang pecah.

\subsection{Bangunan Jetty dari Tumpukan Batu dan Tumpukan Tetrapod}

Triatmodjo (1999) menyatakan bahwa bangunan jetty dari dinding tumpukan batu sangat populer karena berbagai keuntungan yang terdapat pada struktur ini. Dinding tumpukan batu dibangun berlapis dengan lapisan paling luar terdiri dari batu lindung yang paling berat/besar, sedangkan makin ke dalam ukuran batunya semakin kecil.

Dasar perencanaan kontruksi ini adalah lapis luar akan menerima gaya (dari gelombang dan arus) yang paling besar, sehingga ukurannya harus direncanakan sedemikian berat hingga masih stabil. Untuk menentukan berat lapis lindung dapat di pergunakan rumus Hudson sebagai berikut ini:

$$
W=\frac{\gamma_{r H^{3}}}{K_{D}(S R-1)^{3} \cot (\theta)}
$$

dimana:

$\mathrm{W}=$ berat batu lapis luar (ton)

$\mathrm{K}_{\mathrm{D}}=$ koefisien stabilitas batu 
$\begin{aligned} \gamma_{r}= & \text { berat jenis batu, } \gamma_{r}=2.65 \\ & \text { ton } / \mathrm{m}^{3} \\ \mathrm{H}= & \text { tinggi gelombang rencana }\end{aligned}$ (m)

$\mathrm{SR}=$ rapat massa relatip, $\mathrm{SR}=\frac{\gamma_{r}}{\gamma_{w}}$

$\gamma_{w}=$ berat jenis air laut 1.03 ton $/ \mathrm{m}^{3}$

$\theta=$ sudut lereng sisi bangunan

Rumus tebal lapis pelindung berikut:

$\mathrm{t}=\mathrm{n} \times k \Delta \mathrm{x}(\mathrm{w} / \gamma r)^{1 / 3}$

dimana:

$\mathrm{t}=$ tebal lapis $(\mathrm{m})$

$\mathrm{n} \quad=$ jumlah lapis

$k \Delta=$ koefisien lapis

Untuk menghitung lebar puncak jetty dan jumlah butir batu tiap satu luasan menggunakan rumus:

$\mathrm{B}=\mathrm{n} \times k \Delta \times\left(\frac{\mathrm{w}}{\gamma \mathrm{r}}\right)^{1 / 3} \ldots \ldots \ldots \ldots \ldots \ldots . .$.
$\mathrm{N}=\mathrm{A} \times \mathrm{n} \times \mathrm{k} \Delta \times\left(1-\frac{p}{100}\right) \times\left(\frac{\gamma \mathrm{r}}{\mathrm{w}}\right)^{2 / 3}$.

dimana:

$\mathrm{B}=$ lebar puncak $(\mathrm{m})$

$\mathrm{N}=$ jumlah butir batu (nminimum $=3$ )

$k \Delta=$ Koefisien lapis

$\mathrm{W}=$ berat butir batu pelindung (ton)

$\gamma r=$ berat jenis batu pelindung $(\gamma r$ $=2.65 \mathrm{ton} / \mathrm{m}^{3}$ )

$\mathrm{N}=$ jumlah butir batu untuk satu satuan luas permukaan A

$\mathrm{A}=$ luas permukaan $\left(\mathrm{m}^{2}\right)$
$\mathrm{P}=$ Porositas rerata dari lapis pelindung (\%)

\section{METODE PERENCANAAN}

Pada studi ini data-data yang digunakan dalam analisa terdiri dari dua jenis data yaitu data primer yaitu melakukan pengukuran dan pengamatan langsung, dan data sekunder dari studi terdahulu ataupun dari instansi terkait untuk keperluan analisis.

\subsection{Data primer}

Data primer yang dikumpulkan pada penelitian ini adalah data sondir. Data sondir adalah suatu metode uji penekanan yang dilakukan untuk menganalisa daya dukung tanah dan mengukur kedalaman tanah keras.

\subsection{Data sekunder}

Data sekunder yang dikumpulkan pada penelitian ini meliputi sebagai berikut:

\section{Data angin}

Data angin yang digunakan adalah data angin selama 10 tahun terakhir jam-jaman untuk memprediksi tinggi dan periode gelombang

2. Peta batimetri

Data batimetri merupakan data kedalaman muara dan laut dikawasan 
muara sungai, data ini dipergunakan untuk menentukan letek kontruksi jetty.

Adapun langkah langkah penyelesaian sebagai berikut:

1. Mengoreksi data angin akibat pengaruh berbagai faktor.

2. Menganalisis panjang fetch efektif berdasarkan peta lokasi.

3. Analisis pembangkitan gelombang oleh angin.

4. Menggambar mawar gelombang.

5. Menentukan tinggi gelombang rencana dengan kala ulang tertentu.

6. Menganalisis gelombang berupa periode gelombang, cepat rambat gelombang, panjang gelombang dan gelombang pecah

7. Merencanakan dimensi dan stabilitas unit lapis lindung bangunan jetty.

8. Merencanakan rencana anggaran biaya.

\section{HASIL DAN PEMBAHASAN}

\subsection{Analisis Data Angin}

Data kecepatan angin maksimum dalam satuan knot dikonversikan ke dalam satuan metrik (m/detik). Data angin selama sepuluh tahun yang diperoleh dari Badan Meteorologi Klimatologi dan Geofisika (BMKG) Cilacap dianalisis dengan menggunakan software WRPLOT. WRPLOT merupakan program yang digunakan untuk mengetahui gambaran kejadian angin pada kecepatan tertentu dari berbagai arah.

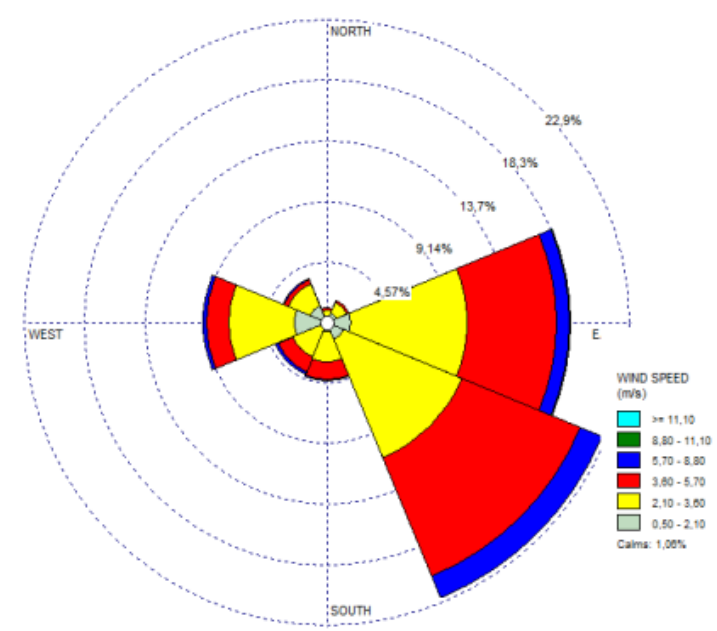

Gambar 1. Windrose Tahun 2008-2017

Analisa angin mengikuti pedoman pada Coastal Engineering Research Center 2006, dengan menggunakan data angin selama 10 tahun. Dari hasil Windrose diatas dapat diketahui, bahwa angin yang berasal dari arah Tenggara lebih mendominasi kecepatan angin kecepatan rata-rata distribusi frekuensi sebesar 3.73 $\mathrm{m} / \mathrm{s}$ selama pengamatan dilakukan. Hasil presentase kejadian angin dari kedelapan mata angin yang paling dominan adalah dari arah tenggara (south east) yaitu 22.40 $\%$. Hasil presentasi kejadian angin dapat dilihat pada Tabel 1. 
Tabel 1. Presentase Arah Kecepatan Angin

\begin{tabular}{|c|c|c|c|c|c|c|c|c|}
\hline No. & $\begin{array}{c}\text { Directions } \\
\text { /Wind } \\
\text { Classes } \\
(\mathrm{m} / \mathrm{s})\end{array}$ & $\begin{array}{c}0.50- \\
2.10\end{array}$ & $\begin{array}{l}2.10- \\
3.60\end{array}$ & $\begin{array}{l}3.60- \\
5.70\end{array}$ & $\begin{array}{l}5.70- \\
8.80\end{array}$ & $\begin{array}{l}8.80- \\
11.10\end{array}$ & $\begin{array}{c}>= \\
11.10\end{array}$ & $\begin{array}{c}\text { Total } \\
(\%)\end{array}$ \\
\hline 1 & $\mathrm{~N}$ & 0.4341 & 0.58222 & 0.13331 & 0.03304 & 0.00114 & 0 & 1.1838 \\
\hline 2 & NE & 0.78388 & 0.8682 & 0.21078 & 0.02051 & 0.00114 & 0.00114 & 1.88565 \\
\hline 3 & $\mathrm{E}$ & 185.831 & 87.116 & 673.138 & 0.99809 & 0.01367 & 0 & 18.3131 \\
\hline 4 & SE & 143.332 & 957.752 & 962.082 & 176.032 & 0.00911 & 0.00114 & 22.4022 \\
\hline 5 & $\mathrm{~S}$ & 0.73375 & 23.038 & 124.191 & 0.09912 & 0 & 0 & 4.37859 \\
\hline 6 & SW & 0.56399 & 224.569 & 120.545 & 0.21078 & 0.01025 & 0.00342 & 4.23959 \\
\hline 7 & $\mathrm{~W}$ & 248.724 & 489.472 & 168.968 & 0.29851 & 0.01025 & 0.00228 & 9.38269 \\
\hline 8 & NW & 143.332 & 176.716 & 0.37143 & 0.0433 & 0.00342 & 0 & 3.61863 \\
\hline & Sub-Total & 972.792 & 309.509 & 212.048 & 346.368 & 0.04899 & 0.00798 & 65.4042 \\
\hline \multicolumn{8}{|c|}{ Calms } & 1.05505 \\
\hline \multirow{2}{*}{\multicolumn{8}{|c|}{$\begin{array}{c}\text { Missing/Incomplete } \\
\text { Total }\end{array}$}} & 33.5407 \\
\hline & & & & & & & & 100 \\
\hline
\end{tabular}

\subsection{Fetch}

Fetch adalah jarak titik pengukuran angin hingga fetch akhir pada daerah yang akan diprakirakan kecepatan anginnya. Jarak ini diukur dengan bantuan Autocad. Fetch diambil pada tiga titik alur pelayaran untuk lebih mewakili kondisi gelombang di alur tersebut. Fetch rerata efektif dihitung dengan menggunakan persamaan
1. Fetch efektif ditinjau dari arah tenggara, selatan dan barat daya (Gambar 2). Hasil analisa Fetch dengan tiga arah mata angin dengan sudut datang $\left(42^{\circ}, 36^{\circ}, 30^{\circ}, 24^{\circ}\right.$, $18^{\circ}, 12^{\circ}, 6^{\circ}, 0^{\circ},-6^{\circ},-12^{\circ},-18^{\circ},-24^{\circ},-30^{\circ},-$ $\left.36^{\circ},-42^{\circ}\right)$ didapat Fetch efektif terpanjang berasal dari arah Selatan yaitu yaitu 164.13 km (Tabel 2).

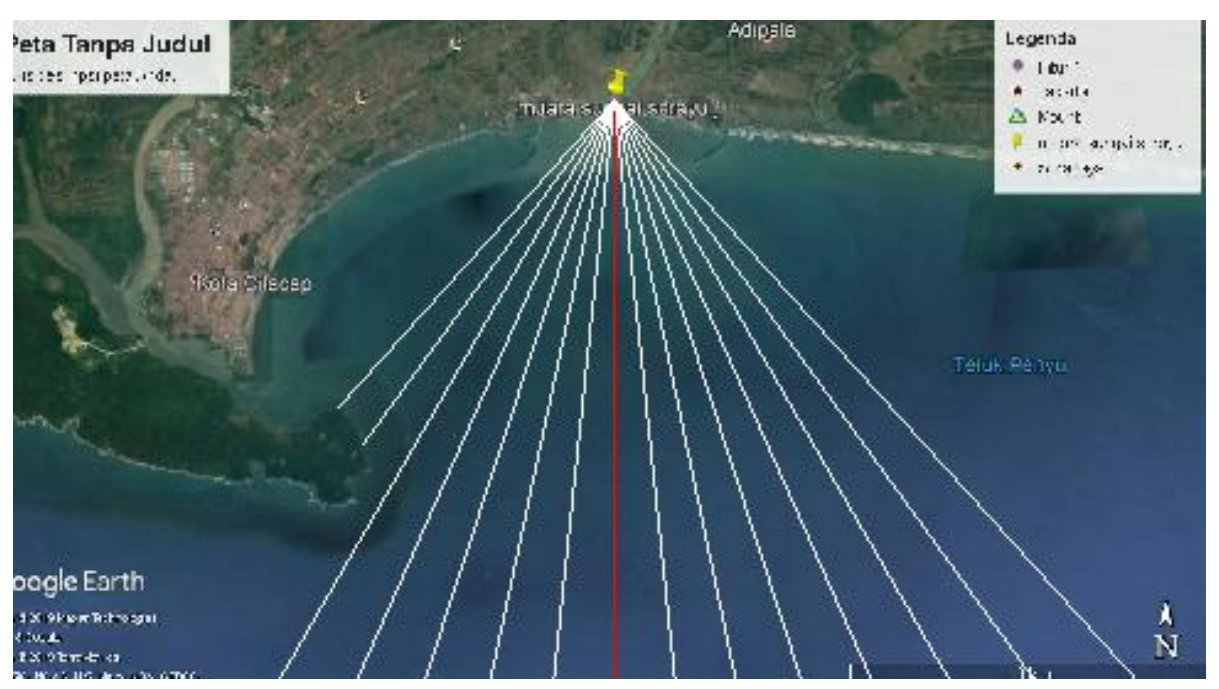

Gambar 2. Fetch Efektif dari Arah Selatan (Zoom in)

(Sumber: Musthafa \& Risdianto, 2020) 
Tabel 2. Perhitungan Fetch Arah Selatan

\begin{tabular}{|c|c|c|c|c|c|c|c|}
\hline No & $\begin{array}{c}\text { Sudut } \\
(\alpha \dot{)})\end{array}$ & $\begin{array}{l}\text { Cos } \\
(\alpha)\end{array}$ & $\begin{array}{c}\text { Jarak Xi } \\
(\mathrm{km})\end{array}$ & $\begin{array}{l}\mathrm{XiCos} \\
(\alpha)\end{array}$ & $\begin{array}{c}\text { Jarak ACAD } \\
\text { (units) }\end{array}$ & $\begin{array}{c}\text { Skala } \\
1: 3.168\end{array}$ & Asli \\
\hline 1 & -42 & 0.74 & 200.00 & 148.63 & 63.14 & 0.3157 & 200.00 \\
\hline 2 & -36 & 0.81 & 200.00 & 161.80 & 63.14 & 0.3157 & 200.00 \\
\hline 3 & -30 & 0.87 & 200.00 & 173.21 & 63.14 & 0.3157 & 200.00 \\
\hline 4 & -24 & 0.91 & 200.00 & 182.71 & 63.14 & 0.3157 & 200.00 \\
\hline 5 & -18 & 0.95 & 200.00 & 190.21 & 63.14 & 0.3157 & 200.00 \\
\hline 6 & -12 & 0.98 & 200.00 & 195.63 & 63.14 & 0.3157 & 200.00 \\
\hline 7 & -6 & 0,99 & 200.00 & 198.90 & 63.14 & 0.3157 & 200.00 \\
\hline 8 & 0 & 1.00 & 0.00 & 0.00 & 0.00 & 0.3157 & 0.00 \\
\hline 9 & 6 & 0.99 & 200.00 & 198.90 & 63.14 & 0.3157 & 200.00 \\
\hline 10 & 12 & 0.98 & 200.00 & 195.63 & 63.14 & 0.3157 & 200.00 \\
\hline 11 & 18 & 0.95 & 200.00 & 190.21 & 63.14 & 0.3157 & 200.00 \\
\hline 12 & 24 & 0.91 & 200.00 & 182.71 & 63.14 & 0.3157 & 200.00 \\
\hline 13 & 30 & 0.87 & 200.00 & 173.21 & 63.14 & 0.3157 & 200.00 \\
\hline 14 & 36 & 0.81 & 16.88 & 13.66 & 5.33 & 0.3157 & 16.88 \\
\hline 15 & 42 & 0.74 & 16.34 & 12.15 & 5.16 & 0.3157 & 16.34 \\
\hline \multicolumn{2}{|c|}{ Jumlah } & \multicolumn{2}{|c|}{ Fecth Efektif } & 2217.56 & \multicolumn{2}{|c|}{$\begin{array}{c}164.13 \\
164130.70\end{array}$} & $\begin{array}{c}\mathrm{km} \\
\mathrm{m}\end{array}$ \\
\hline
\end{tabular}

\subsection{Waverose}

Waverose menggambarkan frekuensi kejadian pada tiap arah mata angin dan kelas ketinggian gelombang pada lokasi dan waktu yang telah ditentukan. Waverose menghasilkan nilai tinggi gelombang air laut dalam satuan centimeter $(\mathrm{cm})$ atau meter $(\mathrm{m})$.

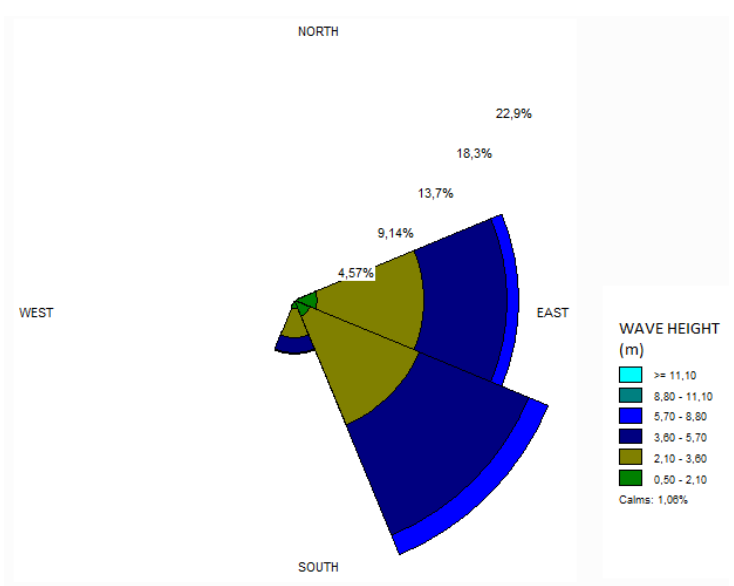

Gambar 3. Waverose 2008-2017
Hasil analisis waverose diatas dapat diketahui, bahwa arah gelombang yang berasal dari arah Tenggara lebih mendominasi dengan tinggi gelombang signifikan sebesar $3.757 \mathrm{~m}$ dimana tinggi gelombang mencapai titik tertingginya.

\subsection{Peramalan Tinggi dan Periode Gelombang oleh Data Angin}

Metode yang digunakan untuk perhitungan gelombang berdasarkan data angin dan medan pembangkitan gelombang adalah metode SMB 1984. Nilai tinggi gelombang signifikan (Hs) dan periode puncak gelombang merupakan fungsi dari kecepatan angin (UA), durasi angin (t), dan panjang fetch (F). Hasil Hs dan Ts dapat dilihat pada Tabel 3. 
Tabel 3. Nilai Tinggi dan Periode Gelombang Signifikan

\begin{tabular}{ccccccc}
\hline Tahun & $\mathrm{Hs}$ & $\mathrm{Ts}$ & $\mathrm{Hs}^{\wedge} 2$ & $\mathrm{Ts}^{\wedge} 2$ & Arah & Kecepatan $(\mathrm{m} / \mathrm{s})$ \\
\hline 2008 & 2.37 & 7.10 & 5.60 & 50.46 & 250 & 9.766 \\
2009 & 2.37 & 7.10 & 5.60 & 50.46 & 120 & 9.766 \\
2010 & 2.16 & 6.89 & 4.66 & 47.47 & 150 & 9.252 \\
2011 & 2.16 & 6.89 & 4.66 & 47.47 & 140 & 9.252 \\
2012 & 2.67 & 7.39 & 7.11 & 54.64 & 240 & 10.794 \\
2013 & 3.32 & 7.95 & 11.02 & 63.23 & 250 & 12.85 \\
2014 & 2.67 & 7.39 & 7.11 & 54.64 & 350 & 10.794 \\
2015 & 3.00 & 7.69 & 8.99 & 59.08 & 240 & 11.822 \\
2016 & 2.85 & 7.56 & 8.11 & 57.09 & 240 & 8.738 \\
2017 & 2.67 & 7.39 & 7.11 & 54.64 & 290 & 10.794 \\
& & Jumlah & 69.99 & 539.18 & & \\
\hline
\end{tabular}

Tinggi gelombang signifikan (Hs)

$$
\text { Hrms }=\sqrt{\frac{\sum \mathrm{nH} 0^{2}}{\sum \mathrm{n}}}=2.646 \mathrm{~m}
$$

Hubungan tinggi gelombang signifikan dengan tinggi gelombang root mean square. $\mathrm{Hs}=1.42 \times \mathrm{Hrms}=1.42 \times$ $2.646=3.757 \mathrm{~m}$.

Periode gelombang signifikan (Ts), dihitung dengan rumus periode gelombang root mean square (Trms).

$$
\text { Trms }=\sqrt{\frac{\sum n T 0^{2}}{\sum n}}=7.343
$$

Kemudian hubungan periode gelombang signifikan dengan periode gelombang root mean square dihitung persamaan 9, sehingga diperoleh hasilnya adalah $\mathrm{Ts}=1.42 \times \mathrm{T}_{\mathrm{rms}}=1.42 \times 7.343=$ $10.427 \mathrm{~s}$.

\subsubsection{Metode Gumbel (Fisher Tippett Type I) \\ Analisa peramalan dengan} menggunakan metode Fisher Tippett Type
I dilakukan dengan mengikuti persamaan 10 sampai dengan persamaan 15. Data probabilitas ditetapkan untuk setiap tinggi gelombang sebagai berikut:

$$
\begin{aligned}
& \left.\mathrm{P}_{(\mathrm{Hs}} \leq \mathrm{Hsm}\right)=1-\frac{m-0.44}{N T+0.12} \\
& \hat{\mathrm{A}}=\frac{n \sum H s m Y m-\sum H s m \sum y m}{n \sum Y m^{2}-\left(\sum Y m\right)^{2}}=0.368 \\
& \mathrm{~B}^{\wedge}=\mathrm{Hsm}-\hat{\mathrm{A}} \mathrm{ym} \quad=2.262 \\
& \mathrm{Hsm}=26.22 / 10=2.622 \\
& \hat{\mathrm{A}} \overline{\mathrm{ym}}=0.368 \times 0.978=0.360
\end{aligned}
$$

Selanjutnya hitungan tinggi gelombang signifikan dengan beberapa periode ulang tertentu tersaji pada Tabel 4 .

\subsubsection{Metode Weibull}

Metode Weibull dihitung dengan menggunakan persamaan 16 sampai persamaan 17.

$$
\begin{aligned}
& \mathrm{P}_{(\mathrm{Hs} \leq \mathrm{Hsm})}=1-\frac{m-0.22-\frac{0.27}{\sqrt{k}}}{N T+0.2+\frac{0.23}{\sqrt{k}}} \\
& \hat{\mathrm{A}}=\frac{n \sum H s m y m-\sum H s m \sum y m}{n \sum y m^{2}-\left(\sum y m\right)^{2}}=0.838 \\
& \mathrm{~B}^{\wedge}=2.622-(0.838 \times 0.888)=1.879
\end{aligned}
$$


Selanjutnya hitungan tinggi dilihat pada Tabel 5, sedangkan gelombang signifikan dengan periode rekapitulasi perhitungan tinggi gelombang ulang berdasarkan metode Weibull dapat kala ulang dapat dilihat pada Tabel 6.

Tabel 4. Gelombang dengan Periode Ulang Tertentu (Metode Fisher Tippett Type I)

\begin{tabular}{|c|c|c|c|c|c|c|c|c|}
\hline $\begin{array}{c}\mathrm{T} \\
\text { Ulang }\end{array}$ & $\mathrm{yr}$ & $\operatorname{Hsr}(\mathrm{m})$ & $\alpha$ & $\Sigma \mathrm{nr}$ & SD & $\Sigma \mathrm{r}$ & $\begin{array}{l}\text { Hsm- } \\
1.28 \sigma \mathrm{r}\end{array}$ & $\mathrm{Hsm}+1.28 \sigma \mathrm{r}$ \\
\hline 2 & 3.34 & 3.491 & \multirow{6}{*}{1.005} & 2.381 & \multirow{6}{*}{0.124} & 0.296 & 3.112 & 3.871 \\
\hline 5 & 4.42 & 3.890 & & 2.725 & & 0.339 & 3.456 & 4.324 \\
\hline 10 & 5.25 & 4.196 & & 2.989 & & 0.372 & 3.720 & 4.673 \\
\hline 25 & 6.37 & 4.607 & & 3.343 & & 0.416 & 4.074 & 5.139 \\
\hline 50 & 7.22 & 4.921 & & 3.614 & & 0.450 & 4.345 & 5.496 \\
\hline 100 & 8.08 & 5.237 & & 3.887 & & 0.484 & 4.618 & 5.856 \\
\hline
\end{tabular}

Tabel 5. Gelombang dengan Periode Ulang Tertentu Metode Weibull

\begin{tabular}{|c|c|c|c|c|c|c|c|c|}
\hline $\begin{array}{c}\mathrm{T} \\
\text { Ulang } \\
\end{array}$ & Yr & $\operatorname{Hsr}(\mathrm{m})$ & $\alpha$ & onr & SD & $\sigma r$ & $\begin{array}{l}\text { Hsm- } \\
1.28 \sigma \mathrm{r}\end{array}$ & $\mathrm{Hsm}+1.28 \sigma \mathrm{r}$ \\
\hline 2 & 0.833 & 2.577 & \multirow{6}{*}{3.966} & 0.733 & \multirow{6}{*}{0.124} & 0.091 & 2.460 & 2.694 \\
\hline 5 & 1.269 & 2.942 & & 1.280 & & 0.159 & 2.738 & 3.146 \\
\hline 10 & 1.517 & 3.151 & & 1.592 & & 0.198 & 2.897 & 3.404 \\
\hline 25 & 1.794 & 3.383 & & 1.939 & & 0.241 & 3.073 & 3.692 \\
\hline 50 & 1.978 & 3.536 & & 2.170 & & 0.270 & 3.191 & 3.882 \\
\hline 100 & 2.146 & 3.677 & & 2.381 & & 0.296 & 3.298 & 4.057 \\
\hline
\end{tabular}

Tabel 6. Rekapitulasi Tinggi Gelombang Kala Ulang

\begin{tabular}{cccccc}
\hline \multirow{2}{*}{$\begin{array}{c}\text { Kala Ulang, } \mathrm{T} \\
\text { (Tahun) }\end{array}$} & \multicolumn{2}{c}{ Weibull } & \multicolumn{2}{c}{$\begin{array}{c}\text { Gumbel (Fisher-Tippet } \\
\text { Type I) }\end{array}$} & \multirow{2}{*}{$\begin{array}{c}\text { Distribusi yang } \\
\text { digunakan }\end{array}$} \\
\cline { 2 - 5 } & YR & $\mathrm{Hsr}=\mathrm{H}(\mathrm{m})$ & $\mathrm{YR}$ & $\mathrm{Hsr}=\mathrm{H}(\mathrm{m})$ & \\
\hline 2 & 0.833 & 2.577 & 3.338 & 3.491 & Gumbel \\
5 & 1.269 & 2.942 & 4.422 & 3.890 & Gumbel \\
10 & 1.517 & 3.151 & 5.254 & 4.196 & Gumbel \\
25 & 1.794 & 3.383 & 6.368 & 4.607 & Gumbel \\
50 & 1.978 & 3.536 & 7.220 & 4.921 & Gumbel \\
100 & 2.146 & 3.677 & 8.080 & 5.237 & Gumbel \\
\hline
\end{tabular}

Hasil analisa tiga metode tersebut selanjutnya dipilih menggunakan gelombang dengan periode ulang Gumbel karena dari dua metode itu diambil paling besar yaitu metode Gumbel Hsr pada kala ulang 50 tahun yaitu 4.921 .

\subsection{Gelombang Pecah}

Menghitung tinggi gelombang pecah dan kedalaman gelombang pecah

Panjang gelombang di laut dalam:

$\mathrm{L}_{0}=1.56 \mathrm{~T}^{2}=1.56 \times 10^{2}=156 \mathrm{~m}$

Cepat rambat gelombang: 


$$
\mathrm{C}_{0}=\frac{156}{10}=15.6 \mathrm{~m} / \mathrm{d}
$$

Untuk kedalaman $5 \mathrm{~m}$ :

$\frac{d}{L o}=\frac{5}{156}=0.03205$

Dari tabel lampiran A-1 (Triatmodjo, 1999) untuk nilai d/Lo $=0.03205$.

Didapat nilai $\mathrm{d} / \mathrm{L}=0.07385$

$$
\begin{aligned}
& \mathrm{L}=\frac{5}{0.07385}=67.705 \mathrm{~m} \\
& \mathrm{C}=\frac{L}{T}=\frac{67.705}{10}=6.771 \mathrm{~m} / \mathrm{d}
\end{aligned}
$$

Untuk menghitung koefisien reflaksi

$$
\begin{aligned}
\operatorname{Sin} \sigma 1 & =\left\{\frac{C 1}{C 0}\right\} \sin \sigma_{0}=\left\{\frac{6,771}{15,6}\right\} \sin 45 \\
& =0,307 ; \sigma 1=17.879^{\circ} \sim 18^{\circ}
\end{aligned}
$$

Koefisien reflaksi:

$$
\mathrm{Kr}=\sqrt{\frac{\cos \sigma 0}{\cos \sigma 1}}=\sqrt{\frac{\cos 45^{\circ}}{\cos 17.879^{\circ}}}=0.862
$$

Tinggi gelombang di laut dalam ekuivalen dihitung dengan persamaan:

$\mathrm{H}^{\prime}{ }_{0}=0.862 \times 4.921=4.242 \mathrm{~m}$.

Hitung tinggi gelombang pecah

$$
\frac{H_{0}^{\prime}}{g T^{2}}=\frac{4.242}{9.81 \times 10^{2}}=0.00432
$$

Untuk nilai $\mathrm{H}^{\prime}{ }_{0} / \mathrm{gT}^{2}=0.00432$ dan kemiringan pantai $\mathrm{m}=0.05$ dari grafik penentuan tinggi gelombang pecah $\mathrm{Hb} / \mathrm{H}^{\prime}{ }_{0}$ $=1.3$ Sehingga tinggi gelombang pecah adalah $\mathrm{Hb}=1.3 \times 4.242=5.50 \mathrm{~m}$. Setelah tinggi gelombang diperoleh selanjutnya dihitung kedalaman gelombang pecah $d_{b}$ dengan grafik penetuan kedalaman gelombang:
$\frac{H_{b}}{g T^{2}}=\frac{5.50}{9.81 \times 10^{2}}=0.00562$

Dengan grafik penentuan kedalaman gelombang maka $\frac{d_{b}}{H_{b}}=1.02$, sehingga kedalaman gelombang pecah adalah $\mathrm{d}_{\mathrm{b}}=$ $1.02 \times 5.50=5.61 \mathrm{~m}$.

\subsection{Perhitungan Bangunan Jetty}

\subsubsection{Bangunan jetty dari tumpukan batu}

Untuk menentukan berat lapis lindung dapat di pergunakan rumus Hudson sebagai berikut ini:

$$
\begin{aligned}
W & =\frac{\gamma_{r H^{3}}}{K_{D}(S R-1)^{3} \cot (\theta)} \\
\mathrm{SR} & =\frac{\gamma_{r}}{\gamma_{w}}=\frac{2.65}{1.03}=2.57 \\
W & =\frac{2.65 \cdot 4.921^{3}}{4(2.57-1)^{3} \cot (2)} \\
& =10.20 \mathrm{ton} / \mathrm{m}^{3}
\end{aligned}
$$

Dalam perencanaan jetty dibuat dalam 2 layer yaitu lapis pelindung, lapis lindung kaki, dan lapis inti, dengan rumus tebal lapis pelindung berikut:

$$
\begin{aligned}
\mathrm{t} & =\mathrm{n} \times k \Delta \mathrm{x}(\mathrm{w} / \gamma r)^{1 / 3} \\
\mathrm{t} & =2 \times 1.15 \times(10.20 / 2.65)^{1 / 3} \\
& =3.60 \mathrm{~m}
\end{aligned}
$$

Untuk menghitung lebar puncak jetty dan jumlah butir batu tiap satu luasan menggunakan rumus:

$$
\begin{aligned}
& \mathrm{B}=\mathrm{n} \times k \Delta \times\left(\frac{\mathrm{w}}{\gamma \mathrm{r}}\right)^{1 / 3} \\
& \mathrm{~B}=3 \times 1.15 \times\left(\frac{10.20}{2.65}\right)^{1 / 3}=5.4 \mathrm{~m}
\end{aligned}
$$




\subsubsection{Bangunan jetty dari tumpukan tetrapod}

Menentukan elevasi puncak bangunn jetty dapat dihitung menggunkan rumus berkut ini.

$$
\begin{aligned}
\mathrm{El}_{\text {puncak }} & =\mathrm{H}_{\text {gelombang pecah }}+\mathrm{H}_{\text {kebebasan }} \\
& =5.50+0.5=6.00 \mathrm{~m}
\end{aligned}
$$

Menentukan tinggi bangunan jetty pada kedalaman 4.5 meter dibawah permukaan air menggunakan rumus berikut ini:

$$
\begin{gathered}
\mathrm{H}_{\text {Banggunan }}=\text { Elv Puncak Bangunan }- \text { Elv } \\
\text { Dasar Laut }=6.00-(-4.5)=10.50 \mathrm{~m} .
\end{gathered}
$$

Untuk menentukan berat lapis lindung dapat di pergunakan rumus Hudson sebagai berikut ini.

$$
\begin{aligned}
W & =\frac{\gamma_{r H^{3}}}{K_{D}(S R-1)^{3} \cot (\theta)} \\
\mathrm{SR} & =\frac{\gamma_{r}}{\gamma_{w}}=\frac{2.4}{1.03}=2.33 \\
W & =\frac{2.4 \times 4.921^{3}}{8 \times(2,33-1)^{3} \times(2)}=7.60 \text { ton }
\end{aligned}
$$

Berat batu lapis inti (core):

$$
\frac{W}{200}=\frac{7.6}{200}=0.038 \text { ton }=40 \mathrm{~kg}
$$

Dalam perencanaan jetty dibuat dalam 2 layer, yaitu lapis pelindung, lapis dan lapis inti, dengan rumus tebal lapis pelindung berikut:

$$
\begin{aligned}
\mathrm{t} & =\mathrm{n} \times k \Delta \mathrm{x}(\mathrm{w} / \gamma r)^{1 / 3} \\
\mathrm{t} & =2 \times 1.04 \times(7.6 / 2.4)^{1 / 3}=3.10 \mathrm{~m}
\end{aligned}
$$

Untuk menghitung lebar puncak jetty menggunakan rumus:

$$
\begin{aligned}
& \mathrm{B}=\mathrm{n} \times k \Delta \times\left(\frac{\mathrm{w}}{\gamma \mathrm{r}}\right)^{1 / 3} \\
& \mathrm{~B}=3 \times 1.04 \times\left(\frac{7,6}{2,4}\right)^{1 / 3}=4.6 \mathrm{~m}
\end{aligned}
$$

Untuk pelindung kaki, digunakan batu pecah bersudut kasar, diketahui dari perhitungan sebelumnya diperoleh berat lapis pelindung utama 7.6 ton.

$$
\frac{W}{10}=\frac{7.6}{10}=0.76 \mathrm{ton}=760 \mathrm{~kg}
$$

Lebar pelindung kaki dapat dihitung dengan rumus:

$$
\begin{aligned}
& \mathrm{B}=\mathrm{n} \times k_{\Delta} \times\left(\frac{\mathrm{w}}{\gamma \mathrm{r}}\right)^{1 / 3} \\
& \mathrm{~B}=3 \times 1.15 \times\left(\frac{0.76}{2.4}\right)^{1 / 3}=2.5 \mathrm{~m}
\end{aligned}
$$

Tinggi pelindung kaki dapat dihitung dengan rumus:

$$
\begin{aligned}
& \mathrm{t}=\mathrm{n} \times k_{\Delta} \times\left(\frac{\mathrm{w}}{\gamma \mathrm{r}}\right)^{1 / 3} \\
& \mathrm{t}=2 \times 1.15 \times\left(\frac{0.76}{2.4}\right)^{1 / 3}=2.00 \mathrm{~m}
\end{aligned}
$$

Tabel 7. Perbandingan Jetty Tumpukan Batu dan Tumpukan Tetrapod

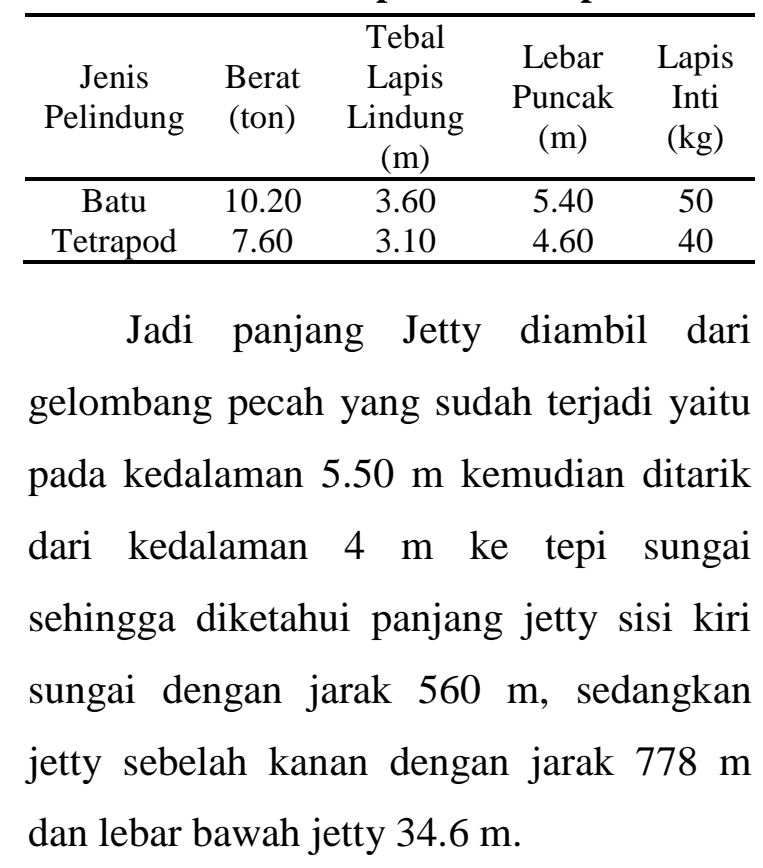




\subsection{Spesifikasi Tetrapod}

Berdasarkan data hasil perhitungan berat butir lapis pelindung pada bagunan jetty, dapat dihitung spesifikasi tetrapod yang akan digunakan. Dari nilai berat butir dapat dihitung besarnya volume berdasarkan rumus dasar berat jenis.

$$
\begin{aligned}
& \gamma=\frac{W}{V} \quad \text { dan } \mathrm{V}=\frac{W}{\gamma} \\
& \text { dimana: } \\
& \gamma=\text { berat jenis }\left(\text { ton } / \mathrm{m}^{3}\right) \\
& \mathrm{W}=\text { berat (ton) } \\
& \mathrm{V}=\text { volume }\left(\mathrm{m}^{3}\right)
\end{aligned}
$$

Diketahui $\mathrm{W}=7.6$ ton maka:

$$
\mathrm{V}=\frac{7.6}{2.4}=3.167 \mathrm{~m}^{3}
$$

Perhitungan volume untuk tetrapod dapat dihitung dengan rumus berikut ini.

$$
\begin{array}{ll}
\mathrm{V} & =0.280 \mathrm{H}^{3} \\
3.167 & =0.280 \mathrm{H}^{3} \\
\mathrm{H}^{3} & =11.311 \\
\mathrm{H} & =2.24 \mathrm{~m}
\end{array}
$$

Berdasarkan nilai $\mathrm{H}$ yang telah diperoleh, dapat dihitung spesifikasi tetrapod yang akan digunakan. Persamaan yang digunakan dalam perhitungan spesifikasi tetrapod antara lain sebagai berikut (Shore Protection Manual Vol. II, pp 7-218):

$$
\begin{array}{ll}
A=0.302 \mathrm{H} & \mathrm{G}=0.215 \mathrm{H} \\
\mathrm{B}=0.151 \mathrm{H} & \mathrm{H}=1 \mathrm{H} \\
\mathrm{C}=0.477 \mathrm{H} & \mathrm{I}=0.606 \mathrm{H}
\end{array}
$$

$$
\begin{array}{ll}
\mathrm{D}=0.470 \mathrm{H} & \mathrm{J}=0.303 \mathrm{H} \\
\mathrm{E}=0.235 \mathrm{H} & \mathrm{K}=1.091 \mathrm{H} \\
\mathrm{F}=0.644 \mathrm{H} & \mathrm{L}=1.201 \mathrm{H}
\end{array}
$$

Tabel 8. Spesifikasi Tetrapod untuk Bangunan Jetty

\begin{tabular}{ccc}
\hline No & Spesifikasi & Tetrapod $(\mathrm{m})$ \\
\hline 1 & A & 0.676 \\
2 & B & 0.338 \\
3 & C & 1.068 \\
4 & D & 1.053 \\
5 & E & 0.526 \\
6 & F & 1.443 \\
7 & G & 0.482 \\
8 & H & 2.240 \\
9 & I & 1.357 \\
10 & J & 0.679 \\
11 & K & 2.444 \\
12 & L & 2.690 \\
\hline
\end{tabular}
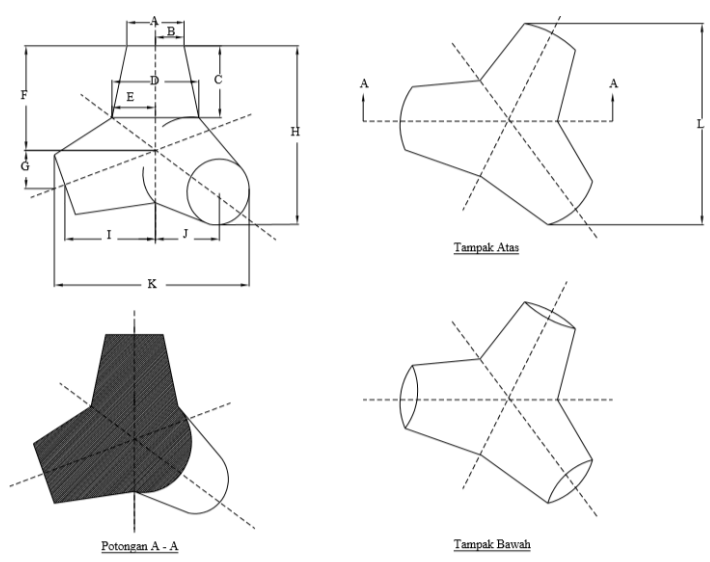

Gambar 4. Dimensi Tetrapod

\subsection{Menetukan Volume Tetrapod}

Adapun cara yang dilakukan untuk menentukan tetrapod adalah berikut ini:

\subsubsection{Cari tinggi seluruh dari tetrapod}

1. Selisih jari - jari $\mathrm{B}$ dan $\mathrm{E}=\mathrm{E}-$ $\mathrm{B}=52.6-33.8=18.8 \mathrm{~cm}$

2. Perbandingan selisih tinggi

$$
C=\frac{18.8}{106.8}=0.176
$$


3. $\quad \mathrm{F}-\mathrm{C}=144.3-106.8=37.5$ $\mathrm{cm}$

4. $\mathrm{C} \times(\mathrm{F}-\mathrm{C})=0.176 \times 37.5=6.6$ $\mathrm{cm}$

5. Jari - jari pusat alas

$\mathrm{r}=6.6+\mathrm{E}=6.6+52.6=59.2$ $\mathrm{cm}$

6. Mencari tinggi puncak kerucut $\frac{\text { jari-jari } B}{0.183}=\frac{33.8}{0.176}=192.045 \mathrm{~cm}$

\subsubsection{Mencari Volume tetrapod 7.6 T}

1. Tinggi dari pusat alas

$$
\begin{aligned}
& \mathrm{T}=\mathrm{C}+192.045=106.8+ \\
& 192.045=298.845 \mathrm{~cm}
\end{aligned}
$$

2. Volume kerucut total

$$
\begin{aligned}
& \mathrm{V}=\frac{1}{3} x \pi \times \mathrm{r}^{2} \times \mathrm{T} \\
& \mathrm{V}=\frac{1}{3} \times \pi \times 52.6^{2} \times 298.845 \\
& \mathrm{~V}=865856.856 \mathrm{~cm}^{3}
\end{aligned}
$$

3. Volume kerucut puncak

$\mathrm{V}=\frac{1}{3} x \pi \times \mathrm{B}^{2} \times \mathrm{T}$

$\mathrm{V}=\frac{1}{3} x \pi \times 33.8^{2} \times 298.845$

$$
\mathrm{V}=357526.315 \mathrm{~cm}^{3}
$$

4. Volume bola pusat tetrapod

$$
\begin{aligned}
& \mathrm{V}=\frac{4}{3} x \pi \mathrm{x} \mathrm{r}^{3} \\
& \mathrm{~V}=\frac{4}{3} x \pi \mathrm{x}(6.6+\mathrm{E})^{3} \\
& \mathrm{~V}=\frac{4}{3} x \pi \times(6.6+52.6)^{3} \\
& \mathrm{~V}=869067.941 \mathrm{~cm}^{3}
\end{aligned}
$$

5. Volume tetrapod 7.6 T

$$
\begin{aligned}
& \mathrm{V}^{\mathrm{t} 7.6}=4 \mathrm{x} \quad\left(\text { vol }_{\text {kerucut }} \text { total }-\right. \\
& \left.\operatorname{vol}_{\text {kerucut puncak }}\right)+\left(\text { vol }_{\text {bola }}\right) \\
& \mathrm{V}^{\mathrm{t} 7.6}=4 \quad \mathrm{x} \quad(865856.856 \quad- \\
& 357526.315)+(869067.941) \\
& \mathrm{V}^{\mathrm{t} 7.6}=2902390.105 \mathrm{~cm}^{3}=2.9 \\
& \mathrm{~m}^{3}
\end{aligned}
$$

Jadi volume tetrapod 7.6 Ton adalah $2.9 \mathrm{~m}^{3}$.

\subsection{Rencana Anggaran Biaya}

Hasil perhitungan rencana anggara biaya pekerjaan pembuatan sepasang jetty di Muara Serayu tersaji pada Tabel 9 berikut:

Tabel 9. Rencana Anggaran Biaya Pembangunan Jetty

\begin{tabular}{clrr}
\hline No & \multicolumn{1}{c}{ Jenis Pekerjaan } & \multicolumn{1}{c}{ Jumlah Harga (Rp) } \\
\hline I & Pekerjaan Persiapan & $472,170,799.00$ \\
II & Pekerjaan tanah & & $117,512,554,858.00$ \\
III & Pekerjaan geotekstil & $924,183,360.00$ \\
IV & Pembuatan 1 buah tetrapod & & $122,981,540,719.00$ \\
V & Pekerjaan pembangunan jetty & $34,528,087,200.00$ \\
VI & Pemasangan tumpukan tetrapod berat 7.6 t & & $122,407,020,608.00$ \\
& & Jumlah Total & $398,825,557,544.00$ \\
& & PPN (10\%) & $39,882,555,754.40$ \\
& & Total + PPN & $438,708,113,298.40$ \\
& & Dibulatkan & $438,708,114,000.00$ \\
\hline
\end{tabular}


Hasil perhitungan RAB menunjukkan ada 6 item pekerjaan dengan total biaya adalah Rp 438,708,114,000.00.

\section{SIMPULAN DAN SARAN}

\subsection{Simpulan}

1. Hasil analisa fetch dengan tiga arah mata angin yaitu, Tenggara, Selatan dan Barat daya didapat fetch efektif terpanjang berasal dari arah Selatan yaitu yaitu $164.13 \mathrm{~km}$.

2. Hasil analisis waverose disimpulkan bahwa bulan agustus merupakan bulan dimana tinggi gelombang mencapai titik tertingginya.

3. Berdasarkan perhitungan gelombang kala ulang dengan kala ulang 50 tahun didapatkan hasil tinggi gelombang (Hsr) sebesar $4.921 \mathrm{~m}$ (metode Gumbell).

4. Hasil tinggi gelombang pecah $5.50 \mathrm{~m}$, kedalaman gelombang pecah $5.61 \mathrm{~m}$, sudut datang gelombang pecah $17.88^{\circ}$.

5. Bangunan jetty di bagi menjadi dua yaitu bangunan jetty sebelah kanan mempunyai panjang 778 $\mathrm{m}$ dan lebar $34.6 \mathrm{~m}$ sedangkan bangunan jetty sebelah kiri mempunyai panjang $560 \mathrm{~m}$ dan lebar $34.6 \mathrm{~m}$.

6. Spesifikasi tetrapod: berat 7.60 ton, lebar $2.690 \mathrm{~m}$, tinggi 2.240 $\mathrm{m}$.

7. Dari perhitungan Rencana Anggaran Biaya (RAB) Perencanaan Bangunan jetty Untuk Penanganan Sedimen Muara Sungai Serayu diperoleh nilai sebesar $\quad \mathrm{Rp}$ $438,708,114,000.00$.

\subsection{Saran}

1. Untuk penyempurnaan desain, diperlukan simulasi kombinasi groin dan tembok laut.

2. Pembangunan jetty ini akan memicu terjadinya erosi dan akresi di sekitar banguan jetty. Hal ini perlu dikaji lebih lanjut agar tidak terjadi pengikisan garis pantai.

\section{DAFTAR PUSTAKA}

Anonim. (1984). Waterways Experiment Station, Corps of Engineer - Shore Protection Manual. Department of The Army.

Anonim. (2006). Waterways Experiment Station, Corps of Engineer - Coastal Engineering Manual. Department of The Army.

Ardantha, I. M., Aryastana, P., Rahadiani, A. A. S. D., \& Candrayana, K. W. 
(2019). Analysis of Coastline Change in Klungkung Regency. The 1st Warmadewa Research and Development Seminar (WARDS), 19. Denpasar: EAI. https://doi.org/10.4108/eai.30-102018.2281487

Aryastana, P., Ardantha, I. M., \& Candrayana, K. W. (2018). Coastline change analysis and erosion prediction using satellite images. MATEC Web of Conferences, 197, $1-5$.

https://doi.org/10.1051/matecconf/20 1819713003

Aryastana, P., Ardantha, I. M., \& Rahadiani, A. A. S. D. (2018). Pemanfaatan Citra Satelit SPOT dalam Analisis Perubahan Garis Pantai di Kabupaten Jembrana. Konferensi Nasional Teknik Sipil 12. Batam: Program Studi Teknik Sipil, Fakultas Teknik, Universitas Atmajaya Yogyakarta.

Aryastana, P., Ardantha, I. M., Rahadiani, A. A. S. D., \& Candrayana, K. W. (2018). Deteksi Perubahan Garis Pantai Di Kabupaten Karangasem Dengan Penginderaan Jauh. Jurnal Fondasi, 7(2), 94-104. https://doi.org/10.36055/jft.v7i2.407 9

Muchlisoh, L. (2016). Perencanaan Struktur Causeway Jetty 2 Proyek Offshore Site Development Kilang Bontang, Kalimantan Timur. Tugas Akhi, Institut Teknologi Sepuluh Nopember Surabaya.

Musthafa, F. A., \& Risdianto, R. (2020). Perencanaan Bangunan Jetty Untuk Penanganan Sedimen Muara Sungai Serayu. Tugas Akhir, Fakultas Teknik, Universitas Wijayakusuma Purwokerto.

Riandi, I., Ikhsan, M., \& Amir, A. (2015).
Perencanaan Ulang Jetty di Muara Batu Putih Meulaboh. Jurnal Teknik Sipil Dan Teknologi Konstruksi, 1(1), 96-107.

Suryawan, I. N., Eryani, I. G. A. P., \& Rahadiani, A. A. S. D. (2019). Perencanaan Bangunan Jetty dari Bahan Bronjong pada Muara Tukad Melangit di Banjar Tegal Besar Kabupaten Klungkung. PADURAKSA, 8(1), 16-26.

Triatmodjo, B. (1999). Teknik Pantai. Yogyakarta: Beta Offset.

Werdi, N. M. K., \& Eryani, I. G. A. P. (2020). Alternatif Perencanaan Jetty di Muara Tukad Pangi Kabupaten Badung. PADURAKSA, 9(1), 102113. https://doi.org/10.22225/pd.9.1.1678. 102-113 